\title{
The Effects of Silibinin on SORT1 Gene Expression and A2780s Ovarian Cancer Cell Line Viability
}

\section{Zahra Lotfi ${ }^{1}$, Elham Salehi ${ }^{1}$, Majid Morovati-Sharifabad ${ }^{1}$, Fatemeh Sarkargar ${ }^{2}$, Gholamhosein Pourghanbari $^{3}$}

${ }^{1}$ Department of Basic Sciences, Faculty of Veterinary Medicine, Ardakan University, Ardakan, Iran

${ }^{2}$ Laboratory of Genetic, Meybod Genetic Research Center, Meybod, Iran

${ }^{3}$ Department of Clinical Sciences, Faculty of Veterinary Medicine, Ardakan University, Ardakan, Iran

\section{*Correspondence to \\ Elham Salehi, Email: :esalehi@ ardakan.ac.ir}

Received March 09, 2021 Accepted July 29, 2021 Published online September 30, 2021

\begin{abstract}
Introduction: Ovarian cancer is one of the deadliest genital cancers among females and mainly originates from epithelial cells. The cancer generally remains asymptomatic until metastasis. Silibinin, a derivative of Silybum marianum, is a flavonoid with anticancer effects against many tumor cells. The sortilin1 (SORT1) gene has been shown to be overexpressed in ovarian tumors. Here, we investigated the effects of silibinin on SORT1 gene expression and the viability of ovarian A2780s cancer cell line.

Methods: The A2780s ovarian cancer cell line was treated with silibinin at the concentrations of 50,100 , and $200 \mu \mathrm{M}$ for 24 hours, and IC $_{50}$ (half-maximal inhibitory concentration) was determined. Then the viability percentage of the cells treated with $100 \mu \mathrm{M}$ silibinin was determined at 24, 48, and 72 hours. After 24 and 48 hours exposure to $100 \mu \mathrm{M}$ silibinin, RNA was extracted, followed by cDNA synthesis and SORT1 gene expression analysis using glyceraldehyde 3-phosphate dehydrogenase $(G A P D H)$ as the reference gene by real-time Polymerase chain reaction (PCR).

Results: Silibinin in a dose- and time-dependent manner reduced the viability of ovarian cancer cells $(P<0.05)$, accompanied by a reduction in SORT1 gene expression.

Conclusion: The present study showed that silibinin had toxic effects against the A2780s ovarian cancer cell line, suggesting this compound as a potential anticancer agent.

Keywords: Ovarian cancer, A2780s, Silibinin, SORT1
\end{abstract}

\section{Introduction}

Ovarian malignancies, among all gynecology cancers, comprise the most important and common tumors. ${ }^{1}$ Despite that women's cancers constitute only $4 \%$ of all cancers, they possess the $5^{\text {th }}$ rank among the leading causes of death across the world. ${ }^{2}$ Various studies have shown that geographical and environmental factors, as well as racial differences and life style factors affect the epidemiology of ovarian cancer. Developed countries, especially northern and western Europe and the United States, have the highest prevalence of ovarian cancer compared to Asia and Africa, ${ }^{3}$ and this cancer is responsible for the death of 22000 women annually in the United States, rendering an incidence risk of one in $75 .^{4}$

One of the causes of fatality of ovarian cancer is its late diagnosis $(70 \%$ of cases are diagnosed at advanced stages). ${ }^{1}$ The survival of women with ovarian cancer depends on the clinical stage of the disease at the time of diagnosis, and early diagnosis extends the survival rate over 5 years in most cases. Today, most cases of ovarian cancer are managed with chemotherapy and surgery, leading to tumor recession in more than $70 \%$; however, relapse has been reported in $90 \%$ of these cases, which is deemed to be untreatable. Early detection is vital to prevent tumor relapse. ${ }^{5}$ Age, familial propensity, diet, job status, environmental pollutants, infrequent pregnancies, infertility, early menstruation, late menopause, hormonal factors, and genetic mutations have been described as risk factors of ovarian cancer while consuming contraceptive pills and oophorectomy have been noted as protective factors. ${ }^{6}$

The sortilin (SORT1) gene (also

(C) 2021 The Author(s); Published by Zabol University of Medical Sciences. This is an open-access article distributed under the terms of the Creative Commons Attribution License (http://creativecommons.org/licenses/by/4.0), which permits unrestricted use, distribution, and reproduction in any medium, provided the original work is properly cited. 
known as neurotensin receptor 3, NTR3), located at Ch 1p21.3-p13.1, has 22 exons in humans. This gene encrypts a copy of 7028 nucleotides (NM002959.4) from which a protein with 831 amino acids is translated. ${ }^{7}$ The protein belongs to Vps10p domain receptors, binding to a number of potential ligands such pro-nerve growth factor (proNGF), lipoprotein lipase (LPL), receptor-associated protein (RAP), neurotensin 3 (NT3), and thyroglobulin. ${ }^{7-10}$ Based on its location and ligands, sortilin 1 shows a variety of functions. While in the trans-Golgi network, it acts as a sorting receptor, on cells' surfaces, the protein mainly works as a clearance receptor. ${ }^{7-10}$ Both sortilin 1 and its ligand, NT3, have been noted to influence the growth of tumor cells. ${ }^{11}$ However, sortilin 1 , as a type I receptor, lacks the necessary domains involved in cellular signaling, but it is an essential part of a receptor complex for proNGF-induced neural cell death. ${ }^{10,12}$ In 1997, Petersen et al identified copies of the SORT1 gene in the brain, heart, thyroid, spinal cord, skeletal muscle, placenta, and testicles, but not in ovaries. ${ }^{7}$ Gene expression analyses have shown a fourfold increase in the expression of the SORT1 gene in cancerous vs. normal ovarian tissues. ${ }^{13}$

In recent years, the role of natural compounds, especially flavonoids, in controlling carcinogenicity and cancer treatment has attracted the attention of many researchers. Flavonoids can contribute to controlling and regulating gene expression and inhibiting carcinogenic enzymes. ${ }^{14}$ Flavonoids are also potent antioxidants, protect cells against oxygenated free radicals, prevent carcinogenic mutations, and according to recent evidence, induce programmed cell death (apoptosis) in cancer cells. ${ }^{14,15}$

Silybum marianum belongs to the Asteraceae plant family and is known by the English name of Milk thistle. The seeds of this plant are a source for a polyphenolic flavonoid known as silymarin, which usually presents in a complex of other derivatives. About $90 \%$ of the silymarin complex is silibinin, followed by other flavonolignans, namely isosilybin, dehydrosilybin, silydianin, silycristin, and taxifolin. ${ }^{16}$ Silibinin is a cell membrane stabilizer, a cellular glutathione enhancer, and a free-radical scavenger. ${ }^{17}$ It has also shown activities such as cell cycle regulation and the inhibition of tumor invasion, angiogenesis, and metastasis, suggesting it as a useful agent for treating several cancers. ${ }^{18}$ The toxicity effects of silibinin against cancer cell lines from stomach, ${ }^{19}$ pancreas, ${ }^{20}$ lung, ${ }^{21}$ glioblastoma, ${ }^{22}$ breast, ${ }^{23}$ prostate, ${ }^{24}$ bladder, ${ }^{25}$ and ovary ${ }^{26}$ tumors have been reported. In the present research, we investigated the effects of silibinin on SORT1 gene expression and cellular viability in the A2780s ovarian cancer cell line.

\section{Methods}

\section{Cell Culture}

The A2780s cell line (Pasteur Institute, Iran, NCBI Code: C461) was cultured in RPMI1640 (Roswell Park Memorial
Institute 1640) (Inoclon, Iran,10RP1500) containing 10\% fetal bovine serum (FBS) (Gibco, Brazil, Cat. No.: 10270106 ) and $1 \%$ penicillin-streptomycin antibiotic (Gibco, Brazil, Cat. No.: 15070-063) and incubated in an optimum condition.

Every 48 hours, the culture medium was replaced. After reaching $70 \%$ confluency, the cells were passaged. At first, the culture medium was slowly poured out, and the cells were washed with PBS (phosphate-buffered saline) (Sigma-Aldrich, USA, Cat. No.: 806552). To detach the cells from flask surface, trypsin-EDTA (1X, $0.25 \%$ solution) (Inoclon, Iran, Cat. No.: 12TR2100) was added. After the isolation of cells, the culture medium supplemented with FBS was added to neutralize trypsin, and after centrifugation (1200 rpm for five minutes), the old medium was discarded, and the new medium was added. Ten microliters of the cellular suspension was poured on the Neubauer slide for counting.

\section{Viability Assay}

A total of $25 \times 10^{4}$ cells were cultured into each well of a 24 well plate. After 24 hours of incubation under optimum conditions, for calculating $\mathrm{IC}_{50}$, the media containing silibinin (Sigma-Aldrich, USA, Cat. No.: 22888-70-6) with the concentrations of 50,100, and $200 \mu \mathrm{M}$ were added to the wells, and the cells were incubated for either 24,48 , or 72 hours. The control group was treated with silibinin-free culture medium for 24 hours. After the elapse of the desired time and following trypsinization, the cells were washed with PBS and centrifuged. Finally, $10 \mu \mathrm{L}$ of the cell suspension was poured on the Neubauer slide for counting viable cells.

Dimethyl sulfoxide (DMSO) was used as a solvent for preparing silibinin stock solution with the concentration of $482.42 \mathrm{M}$. The final concentration of DMSO in the control well was equal to that in treated wells.

\section{RNA Extraction}

One million cells were cultured into each well of a 6-well plate and exposed to $100 \mu \mathrm{M}$ of silibinin for 24 and 48 hours. The control groups were treated with the culture medium for 24 and 48 hours. The cells were centrifuged after separation from the plate surface, and the cell plaques were quickly transferred to a nitrogen tank to maintain RNA. High Pure RNA Isolation Kit (Roche, Germany, Cat. No.: 11828665001) was used to extract RNA according to the provided guidelines. Electrophoresis was performed on agarose gel to ensure the quality of the extracted RNA. The presence of two clear bands on the gel confirmed the good quality of the extracted RNA. For quantitative investigation of the extracted RNA, the optical absorption ratios of 260/280 and 260/230 $\mathrm{nm}$ were determined by the nanodrop technique. These ratios were between 1.7 and 1.9 in all samples, indicating a high-purity RNA. 


\section{cDNA Synthesis}

RevertAid First Strand cDNA Synthesis Kit (Thermo Fisher Scientific, Lithuania, Cat. No.: K1622) was used for this purpose, employing $1 \mu \mathrm{L}$ RNA, $1 \mu \mathrm{L}$ Random Hexamer, $6 \mu \mathrm{L}$ DEPC (diethyl pyrocarbonate) water, which were mixed, spined, and incubated in a thermal cycler for five minutes at $65^{\circ} \mathrm{C}$. Afterwards, $5 \mathrm{x}$ reaction buffer $(4 \mu \mathrm{L})$, dNTP (deoxynucleoside triphosphate) $2 \mu \mathrm{L}$, and RT (reverse transcriptase) enzyme $(1 \mu \mathrm{L})$ were added to the sample, and the final volume was reached $20 \mu \mathrm{L}$ with D.D.W (distilled deionized water). The thermal program included $25^{\circ} \mathrm{C}$ for 10 minutes, $42^{\circ} \mathrm{C}$ for 60 minutes, and $65^{\circ} \mathrm{C}$ for 10 minutes. Using a nanodrop (Stat Fax 2000, USA) device, the synthesized cDNA quality was ensured.

\section{Real-Time PCR}

The sequences of the SORT1 and GAPDH genes were attained from the NCBI site, and the primers were designed at exon-exon junctions using gene runner software and blasted also in the NCBI (Table 1).

PCR Master Mix Kit (SuperArray, USA, Cat. No.: PA012) was used for gene amplification. Ten $\mu \mathrm{L}$ SYBR green, $1 \mu \mathrm{L}$ of the forward and reverse primers of each gene, and $5 \mu \mathrm{L}$ cDNA were added into a microtube, and D.D.W. was added to the reaction mixture to reach 20 $\mu \mathrm{L}$. The temperature-time program included $95^{\circ} \mathrm{C}$ for 1 minute, followed by $95^{\circ} \mathrm{C}$ for 15 seconds and $60^{\circ} \mathrm{C}$ for 60 seconds. To ensure the specificity of the product, the melting curve was investigated. All the experiments were conducted in triplicate, and gene expression was measured by the $2^{-\Delta \Delta \mathrm{Ct}}$ method.

\section{Statistical Analysis}

Data analysis was conducted in SPSS 25 software, and comparisons between the groups were conducted by oneway ANOVA and Tukey's post hoc tests. Mean \pm standard deviation was used to express the data, and $P<0.05$ was the statistical significance cut off.

\section{Results}

$I_{50}$ Assay

The percentage of living cells in the studied groups (treated with the concentrations of 50,100, and $200 \mu \mathrm{M}$ of silibinin) after 24 hours has been shown in Figure 1. Silibinin at all three concentrations led to a remarkable decrease in the ratio of alive cells in a dose-dependent manner compared to the control group. The $\mathrm{IC}_{50}$ of silibinin after 24 hours was $166.7 \mu \mathrm{M}$. The concentration of $100 \mu \mathrm{M}$, at which $60 \%$ of the cells survived, was selected for further studies.

\section{Investigation of Cell Viability at Different Times}

Figure 2 shows the percentage of living cells (mean \pm SD) in the control group and those treated with $100 \mu \mathrm{M}$ silibinin after 24,48 , and 72 hours, showing a significant decline in the ratio of living cells in silibinin-treated groups vs. control, as well as in 48- and 72-hour vs. 24 -hour treated groups. These findings suggested that silibinin could time-dependently reduce A2780s cells' viability.

\section{SORT1 Gene Expression}

As it can be seen in Figure 3, the expression level of the SORT1 gene decreased significantly after exposure to 100 $\mu \mathrm{M}$ silibinin for 24 and 48 hours compared to the control group. Also, the gene expression of SORT1 was lower in the cells treated with silibinin for 48 hours vs. 24 hours, but this decrease was not statistically significant (Table 2).

\section{Discussion}

The present findings showed that silibinin dose- and time-dependently reduced the viability of an ovarian cancer cell line, accompanied by a significant reduction in SORT1 gene expression, which is abnormally expressed in ovarian cancer cells. These results are in accordance with the observations of other researchers.

Zhang et al showed that silibinin had inhibitory effects against the SW1990 and AsPC-1 cell lines in a dosedependent and time-dependent form. In the recent study, silibinin decreased Bcl-2 expression, inhibited cell proliferation, and boosted p15INK4B expression, arresting the cell cycle at the G1 stage. By triggering the signaling pathway of JNK/stress-activated protein kinase, silibinin could ignite apoptosis via the mitochondrial pathway in human pancreatic cancer cells. ${ }^{20}$ Silibinin can also inhibit angiogenesis, preventing hypoxia, endothelial cell formation, and cancer cells' invasion and proliferation. ${ }^{27}$ Silibinin, as a flavonoid, has been noted to promote its anti-cancer effects via inducing apoptosis in vitro and in vivo and targeting various signaling mediators, such as Bcl-2, VEGF, PI3K/AKT, Cip1/p21 $\beta$-Catenin, COX-2/ PGE2, STAT3, MAPK/ERK, and Kip1/p27, in different types of cancer cells. ${ }^{28}$ Silibinin-treated Hep3B and HepG2 cells showed a significant reduction in growth, which was associated with the induction of apoptosis. In addition,

Table 1. The Sequences of the SORT1 and GAPDH Genes' Primers for Real-Time PCR

\begin{tabular}{|c|c|c|c|c|c|}
\hline Gene & Primer Sequence ( $5^{\prime}$ to $\left.3^{\prime}\right)$ & Primer Tm & Size of PCR Product (bp) & GenBank Accession Number & Efficiency $(\%)$ \\
\hline \multirow{2}{*}{ SORT1 } & F: TCAGAGCCGAATGCCGTAG & 53.7 & \multirow{2}{*}{125} & \multirow{2}{*}{ NM_002959 } & \multirow{2}{*}{93.5} \\
\hline & R: CCTTCCAGCATCTTTGTCCAG & 53.8 & & & \\
\hline \multirow{2}{*}{ GAPDH } & F: TCСТССАССТTTGАСGСТG & 53.3 & \multirow{2}{*}{102} & \multirow{2}{*}{ NM_002046 } & \multirow{2}{*}{96.4} \\
\hline & R: CACCACССТGTTGCTGTAGC & 52.9 & & & \\
\hline
\end{tabular}




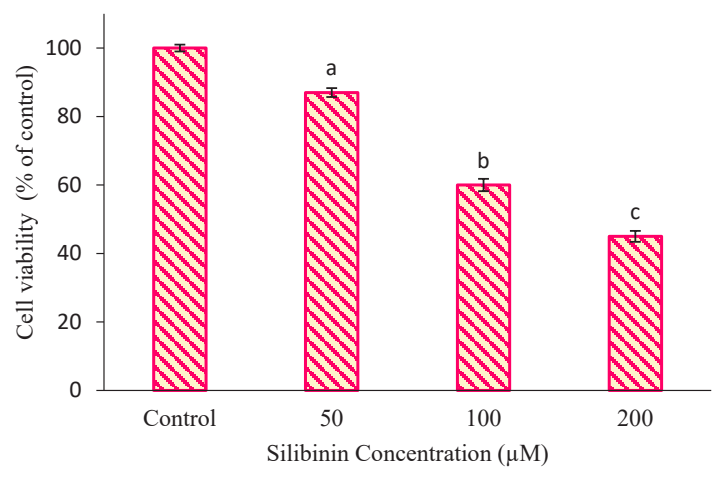

Figure 1. Living Cell Ratios in the Study Groups. The A2780s cell line was treated with the concentrations of 50,100, and $200 \mu \mathrm{M}$ of silibinin for 24 hours. Each of the letters of a, b, and c expresses a significant difference compared to the control and other groups $(P<0.05)$.

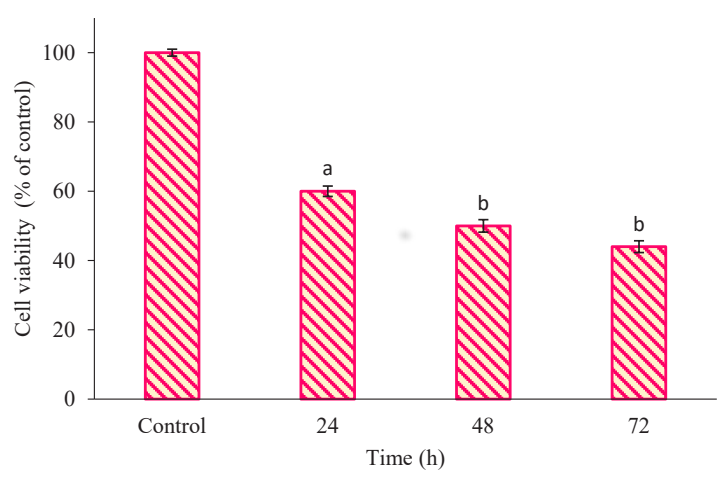

Figure 2. The Percentage of Living Cells in the Cells Treated With $100 \mu \mathrm{M}$ of Silibinin for 24, 48, and 72 Hours Compared to the Control Group. Each of the letters of $\mathrm{a}$ and $\mathrm{b}$ expresses a significant difference compared to the control and other groups $(P<0.05)$.

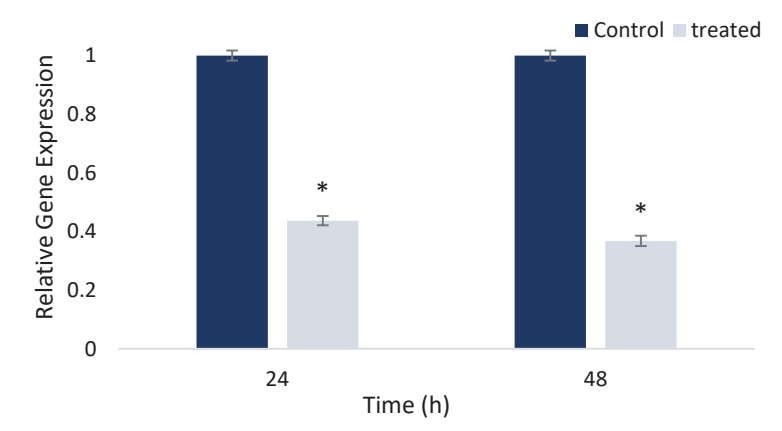

Figure 3. SORT1 Gene Expression in the Control Group and the Cells Treated With $100 \mu \mathrm{M}$ of Silibinin for 24 and 48 Hours. The * symbol expresses a significant difference compared to the control group $(P<0.05)$.

Table 2. Comparison of SORT1 Gene Expression in Different Groups

\begin{tabular}{lcc}
\hline Groups & Fold Change & Interpretation \\
\hline $24 \mathrm{~h}$ vs. control & 0.437 & Downregulation: 2.29 -fold \\
$48 \mathrm{~h}$ vs. control & 0.368 & Downregulation: 2.72-fold \\
$48 \mathrm{~h}$ vs. $24 \mathrm{~h}$ & 0.842 & Downregulation: 1.19-fold \\
\hline
\end{tabular}

HepG2 cells displayed an arrest in cell cycle progression at G1 while Hep3B cells seemed to fail progressing from the G2 to M phase. Silibinin also induced the kip1/p27 but suppressed D3, D1, E, CDK-2, and CDK-4 kinasedependent cyclins in both of the cell lines. ${ }^{29}$ In another study, CD82 gene expression was shown to be upregulated in silibinin-treated PC-3 prostate cancer cells, suppressing metastasis. $^{24}$

The human gastric cancer cells (SGC7901) treated with silibinin showed decreased ability to invade and migrate, which was associated with suppressed p38MAPK signaling and reduced MMP-9 and MMP-2 expression. ${ }^{19}$ Silibinin also promoted TGF- $\beta 2$-mediated suppression of FN, MMP-2, and MMP-9 and suppressed the metastatic potential of TNBC breast cancer cells. ${ }^{23}$ Silibinin was also found to suppress SKOV-3 cells' proliferation, showing synergism with paclitaxel to strengthen the effects of this drug when used in combination therapy, accompanied by the upregulation of P21 and P53 tumor suppressor genes in the cells treated with silibinin + paclitaxel. $^{30}$ The findings of another study on human ovarian cancer cells showed that silibinin suppressed SKOV3 and OVCAR8 cells' DNA synthesis, proliferation, and clonogenic ability by inhibiting the HRG/HER3 pathway. According to our observation, reduced cyclin D1 and survival by silibinin and increased P27 and FOXO1 led to cell cycle inhibition at the G1/S stage. In addition, silibinin decreased the invasive potentials of epithelial ovarian cancer cells by inhibiting the HRG/HER3 pathway and suppressing cathepsin B activity. ${ }^{26}$ In 2014, Fan et al reported that P53, P21, and P27 upregulation and CDK2 downregulation in silymarin-treated cells were accompanied by a significant dose- and time-dependent reduction in ovarian cancer cells' growth and cell cycle arrest at the G1/S stage. Silymarin seemed to induce cytochrome C release from mitochondria partly by disrupting membrane potential and promoting apoptosis by activating caspase 3 and 9 and Bax and decreasing Bcl-2 in PA- 1 and A2780s cells. ${ }^{31}$ Also, silibinin exploited apoptotic pathways, at least in part, to induce death in the two cell lines of A2780 and SKOV3 and suppressed the ERK and Akt pathways to promote anti-cancer effects in ovarian cancer cells. ${ }^{32}$ The results of this study confirmed the previous research suggesting silibinin as an effective anticancer substance against the A2780s cell line.

\section{Conclusion}

Silibinin dose- and time-dependently suppressed the growth of and reduced the viability of the ovarian cancer cell line, A2780s. This effect was associated with reduced SORT1 gene expression in these cells. The present study confirmed previous research suggesting silibinin as a toxic agent against ovarian cancer cells, including the A2780s cell line, which can be used to develop anticancer drugs. 


\section{Ethical Approval}

This experimental study on ovarian A2780s cancer cell line was conducted at Cell and Developmental Lab of the Basic Sciences Department, Faculty of Veterinary Sciences, (ethical code: IR.YAZD.REC.1399.035).

\section{Conflict of Interests}

No conflict or competing financial interests exist.

\section{Financial Support}

No funding.

\section{Acknowledgments}

The authors of the article consider it necessary to appreciate and thank the sincere cooperation of university laboratory officer, Mr. Mohsen Rashidi.

\section{References}

1. Rauh-Hain JA, Krivak TC, Del Carmen MG, Olawaiye AB. Ovarian cancer screening and early detection in the general population. Rev Obstet Gynecol. 2011;4(1):15-21.

2. Siegel R, Ma J, Zou Z, Jemal A. Cancer statistics, 2014. CA Cancer J Clin. 2014;64(1):9-29. doi:10.3322/caac.21208

3. Zayyan MS, Ahmed SA, Oguntayo AO, Kolawole AO, Olasinde TA. Epidemiology of ovarian cancers in Zaria, Northern Nigeria: a 10-year study. Int J Womens Health. 2017;9:855-860. doi:10.2147/ijwh.s130340

4. Jayson GC, Kohn EC, Kitchener HC, Ledermann JA. Ovarian cancer. Lancet. 2014;384(9951):1376-1388. doi:10.1016/ s0140-6736(13)62146-7

5. Berry NB, Bapat SA. Ovarian cancer plasticity and epigenomics in the acquisition of a stem-like phenotype. J Ovarian Res. 2008;1:8. doi:10.1186/1757-2215-1-8

6. Permuth-Wey J, Sellers TA. Epidemiology of ovarian cancer. Methods Mol Biol. 2009;472:413-437. doi:10.1007/978-160327-492-0_20

7. Petersen CM, Nielsen MS, Nykjaer A, et al. Molecular identification of a novel candidate sorting receptor purified from human brain by receptor-associated protein affinity chromatography. J Biol Chem. 1997;272(6):3599-3605. doi:10.1074/jbc.272.6.3599

8. Nielsen MS, Jacobsen C, Olivecrona G, Gliemann J, Petersen CM. Sortilin/neurotensin receptor-3 binds and mediates degradation of lipoprotein lipase. J Biol Chem. 1999;274(13):8832-8836. doi:10.1074/jbc.274.13.8832

9. Botta R, Lisi S, Pinchera A, et al. Sortilin is a putative postendocytic receptor of thyroglobulin. Endocrinology. 2009;150(1):509-518. doi:10.1210/en.2008-0953

10. Nykjaer A, Lee R, Teng KK, et al. Sortilin is essential for proNGFinduced neuronal cell death. Nature. 2004;427(6977):843848. doi:10.1038/nature02319

11. Elek J, Pinzon W, Park KH, Narayanan R. Relevant genomics of neurotensin receptor in cancer. Anticancer Res. 2000;20(1A):53-58

12. Arnett MG, Ryals JM, Wright DE. Pro-NGF, sortilin, and p75NTR: potential mediators of injury-induced apoptosis in the mouse dorsal root ganglion. Brain Res. 2007;1183:32-42. doi:10.1016/j.brainres.2007.09.051

13. Donninger $\mathrm{H}$, Bonome $\mathrm{T}$, Radonovich $\mathrm{M}$, et al. Whole genome expression profiling of advance stage papillary serous ovarian cancer reveals activated pathways. Oncogene. 2004;23(49):8065-8077. doi:10.1038/sj.onc.1207959

14. Ramos S. Cancer chemoprevention and chemotherapy: dietary polyphenols and signalling pathways. Mol Nutr Food Res. 2008;52(5):507-526. doi:10.1002/mnfr.200700326

15. Kauntz H, Bousserouel S, Gosse F, Marescaux J, Raul F. Silibinin, a natural flavonoid, modulates the early expression of chemoprevention biomarkers in a preclinical model of colon carcinogenesis. Int J Oncol. 2012;41(3):849-854. doi:10.3892/ijo.2012.1526

16. Kroll DJ, Shaw HS, Oberlies NH. Milk thistle nomenclature: why it matters in cancer research and pharmacokinetic studies. Integr Cancer Ther. 2007;6(2):110-119. doi:10.1177/1534735407301825

17. Kauntz H, Bousserouel S, Gossé F, Raul F. The flavonolignan silibinin potentiates TRAIL-induced apoptosis in human colon adenocarcinoma and in derived TRAIL-resistant metastatic cells. Apoptosis. 2012;17(8):797-809. doi:10.1007/s10495012-0731-4

18. Yousefi M, Ghaffari SH, Zekri A, Hassani S, Alimoghaddam K, Ghavamzadeh A. Silibinin induces apoptosis and inhibits proliferation of estrogen receptor (ER)-negative breast carcinoma cells through suppression of nuclear factor kappa B activation. Arch Iran Med. 2014;17(5):366-371.

19. Lu S, Zhang Z, Chen M, Li C, Liu L, Li Y. Silibinin inhibits the migration and invasion of human gastric cancer SGC7901 cells by downregulating MMP-2 and MMP-9 expression via the p38MAPK signaling pathway. Oncol Lett. 2017;14(6):75777582. doi:10.3892/ol.2017.7080

20. Zhang X, Liu J, Zhang P, et al. Silibinin induces G1 arrest, apoptosis and JNK/SAPK upregulation in SW1990 human pancreatic cancer cells. Oncol Lett. 2018;15(6):9868-9876. doi:10.3892/ol.2018.8541

21. Mateen S, Tyagi A, Agarwal C, Singh RP, Agarwal R. Erratum: silibinin inhibits human nonsmall cell lung cancer cell growth through cell-cycle arrest by modulating expression and function of key cell-cycle regulators. Mol Carcinog. 2010;49(9):849. doi:10.1002/mc.20667

22. Chakrabarti M, Ray SK. Anti-tumor activities of luteolin and silibinin in glioblastoma cells: overexpression of miR-7-1$3 p$ augmented luteolin and silibinin to inhibit autophagy and induce apoptosis in glioblastoma in vivo. Apoptosis. 2016;21(3):312-328. doi:10.1007/s10495-015-1198-x

23. Kim S, Han J, Jeon $M$, et al. Silibinin inhibits triple negative breast cancer cell motility by suppressing TGF- $\beta 2$ expression. Tumour Biol. 2016;37(8):11397-11407. doi:10.1007/s13277016-5000-7

24. Mokhtari M, Shokrgozar MA, Motamed N, et al. Up regulation of CD82 gene in prostate cancer PC-3 cell line treated with silibinin. Pathobiology Research. 2010;13(3):41-52. [Persian].

25. de Oliveira DT, Sávio ALV, de Castro Marcondes JP, et al. Cytotoxic and toxicogenomic effects of silibinin in bladder cancer cells with different TP53 status. J Biosci. 2017;42(1):91101. doi:10.1007/s12038-016-9654-5

26. Momeny M, Ghasemi R, Valenti G, et al. Effects of silibinin on growth and invasive properties of human ovarian carcinoma cells through suppression of heregulin/HER3 pathway. Tumour Biol. 2016;37(3):3913-3923. doi:10.1007/s13277-015-42206

27. Deep G, Kumar R, Nambiar DK, et al. Silibinin inhibits hypoxia-induced HIF-1 $\alpha$-mediated signaling, angiogenesis and lipogenesis in prostate cancer cells: In vitro evidence and in vivo functional imaging and metabolomics. Mol Carcinog. 2017;56(3):833-848. doi:10.1002/mc.22537

28. Tiwari P, Mishra K. Silibinin in cancer therapy: a promising prospect. Cancer Res Front. 2015;1(3):303-318. 
doi:10.17980/2015.303

29. Varghese L, Agarwal C, Tyagi A, Singh RP, Agarwal R. Silibinin efficacy against human hepatocellular carcinoma. Clin Cancer Res. 2005;11(23):8441-8448. doi:10.1158/10780432.ccr-05-1646

30. Pashaei-As| F, Pashaei-As| R, Khodadadi K, Akbarzadeh A, Ebrahimie E, Pashaiasl M. Enhancement of anticancer activity by silibinin and paclitaxel combination on the ovarian cancer. Artif Cells Nanomed Biotechnol. 2018;46(7):1483-1487. doi: 10.1080/21691401.2017.1374281
31. Fan L, Ma Y, Liu Y, Zheng D, Huang G. Silymarin induces cell cycle arrest and apoptosis in ovarian cancer cells. Eur J Pharmacol. 2014;743:79-88. doi:10.1016/j. ejphar.2014.09.019

32. Cho HJ, Suh DS, Moon SH, et al. Silibinin inhibits tumor growth through downregulation of extracellular signalregulated kinase and Akt in vitro and in vivo in human ovarian cancer cells. J Agric Food Chem. 2013;61(17):4089-4096. doi:10.1021/jf400192v 